\title{
La vinculación de elementos cotidianos a las ciudadanías alternativas: el trabajo por cuenta propia y las prácticas de solidaridad. Un estudio de caso en Zamora (Michoacán, México)
}

\author{
Isaac Riquelme* \\ COLECTIVO DE ESTUDIO Y TRABAJO SOCIAL, MADRID
}

En el proceso inclusivo que ha experimentado la ciudadanía los elementos asociados a ella parecen haber perdido cierto significado. A partir de este fenómeno, se han desarrollado formas alternativas de ciudadanía vinculadas a elementos aparentemente innovadores. En el estudio de éstos, a través de las formas de ciudadanía de un barrio periférico de una ciudad media de México, han destacado particularmente el trabajo por cuenta propia en el sector informal y las prácticas de solidaridad y apoyo mutuo entre vecinos.

(Ciudadanía, informalidad, cotidianidad, trabajo, solidaridad)

Para mí el gobierno no me ayuda, más bien si se da cuenta que te está yendo bien te va a chingar. Ponle que no te chinguen del todo, te van a dar chance dos o tres meses para que registres pero si lo hago... ¿qué me darían?

Don Roberto (39). Mecánico de bombas de refrigeración automotrices en su domicilio.

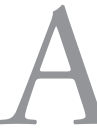

lo largo de este artículo pretendo revisar con especial atención dos elementos que frecuentemente se han dejado fuera del estudio de las ciudadanías y que podrían tener especial relevancia en el abordaje de las mismas; particularmente en las ciudadanías que se dan los estados-nación postmodernos dentro de un contexto globalizado. Dichos elementos han sido estudiados anteriormente por las ciencias sociales pero su vinculación con la génesis y práctica de nuevas formas de ciudadanía ha sido indirecta o inexistente. Me estoy

*info@isaacriquelme.com 
refiriendo a determinadas formas de trabajo por cuenta propia y a ciertas prácticas de solidaridad, particularmente entre convecinos.

Aproximarse al concepto de ciudadanía o ciudadano es una tarea ambiciosa. Los contenidos que han llenado dicha categoría han variado bastante según el periodo temporal y la ubicación geográfica. En cualquier caso, son conceptos complejos y susceptibles de muy diversos enfoques que incluso, como explicaba Rousseau, son difíciles de entender (Pérez Ledesma 2007, 21).

Con el fin de exponer el caso adecuadamente, me gustaría, en primer lugar, ubicar el estudio de caso y definir los dos elementos que tuvieron especial relevancia durante el mismo en la aproximación a las formas de relación con las instituciones de carácter estatal para posteriormente revisar su vínculos con el concepto moderno de ciudadanía y las diversas formas de ciudadanía contemporáneas.

\section{El ESTUdio DE CASO}

El colectivo a través del cual desarrollé la teoría que presento en este artículo reside en barrio Ejidal Sur, ubicado en la ciudad de Zamora, en el estado de Michoacán (México). La ciudad es simultáneamente un lugar emisor y receptor de migrantes (González y González 2009, 235). De los individuos que se desplazan hacía el municipio de Zamora, destacan muy significativamente los que proceden de municipios circundantes (Ibid., p. 153); en la emisión de personas destaca principalmente la migración a Estados Unidos y, muy secundariamente, al estado del Jalisco o a la capital de la República.

En el pueblo se puso escaso el trabajo y unos primos que teníamos en $\mathrm{Za}$ mora nos decían: ¡vénganse para acá! Acá esta bueno el trabajo.

Don José (70). Refiriéndose a cuando llegó a Zamora proveniente de un rancho cercano a Urepétiro hace 58 años.

La ciudad funciona como centro comercial regional de la zona, particularmente para las localidades que constituyen su municipio; la actividad comercial principal es la agricultura. La configuración demográfica actual del municipio se vio muy influida por las altas 
tasas de crecimiento de la población que se dieron a mediados del siglo $\mathrm{xx}$, coincidiendo con un boom agrícola cuyo protagonista principal fue el cultivo y la exportación de la fresa; una gran parte de ésta se dirige al extranjero, especialmente a Estados Unidos.

A raíz del intenso crecimiento urbano comenzaron a construirse grandes zonas dedicadas a viviendas; muchas de ellas destinadas a los nuevos trabajadores migrantes que se asentaron en la ciudad. La construcción de colonias populares aceleró intensamente el crecimiento urbano a partir de los años sesenta; en esta época "el estado, con el fin de disminuirse presiones sociales, otorga todas las facilidades a formas de urbanización en las cuales parece asociarse el concepto de popular con la idea de un pedazo de tierra prácticamente carente de servicios" (Ortiz 1998, 24). El barrio que se presenta en este estudio es uno de éstos.

Generalmente, el adjetivo popular unido a sustantivos relativos a la vivienda (barrio, casa, asentamiento, etcétera) suele estar asociado a conceptos como problema, marginación, apropiación ilegal o irregular del suelo, falta de servicios básicos y sobre todo autoconstrucción. Considero que la vivienda popular en México puede ser definida con base en cuatro elementos principales.

En primer lugar, se puede considerar vivienda popular a aquella que está asentada sobre terrenos sobre los que no se consiguió una titularidad directamente sino por la que hubo (o hay) que litigar. En segundo lugar, aquellas que se construyeron sin respetar los normativas urbanísticas vigentes en el momento de su construcción. Tercero, aquellas viviendas que en el momento de su construcción no tuvieron acceso a los servicios básicos que hacen una vivienda habitable: agua corriente, drenaje y electricidad, principalmente. La consecución de esos y otros servicios para las viviendas populares supuso (o supone) un proceso largo de reivindicaciones que en ocasiones lleva desembolsos económicos asociados. El cuarto y último elemento es que, en un barrio de viviendas populares, un número significativo de viviendas han sido construidos mediante el proceso de "autoconstrucción en etapas". ${ }^{1}$

${ }^{1}$ Este proceso podría definirse en líneas generales como la construcción de la vivienda 
En un contexto generado a raíz de fuertes corrientes migratorias (del medio rural al urbano) y de procesos de aceleración y desaceleración económica puede ubicarse el desarrollo de nuevas formas de relación entre los individuos y el entorno donde se vive (barrio), las maneras con las que uno se gana la vida (trabajo), los apoyos con los que cuenta (formas de solidaridad) y, finalmente, las relaciones con las instituciones de carácter estatal (ciudadanía). Tanto la ciudad como el barrio cuentan con algunas características específicas que las hacen especialmente indicadas para el estudio de este fenómeno. En términos amplios, podrían enumerarse el alto índice de trabajo por cuenta propia, la participación generalizada en prácticas de solidaridad informal y la condición de asentamiento popular reciente donde se ha tenido que reivindicar la titularidad de los terrenos y el acceso a determinados servicios.

\section{El barrio Ejidal Sur}

La forma en la que decidí estudiar el barrio fue viviendo en el mismo. La totalidad de los datos etnográficos recogidos en esta investigación se obtuvieron en un periodo superior al año y medio, desde enero del 2009 hasta septiembre de 2010. En este tiempo fui simultáneamente vecino, trabajador e investigador del barrio Ejidal Sur. Mi residencia estuvo siempre ubicada en este barrio durante dicho periodo aunque, para ampliar mi perspectiva sobre el mismo, tuve cuatro residencias diferentes dentro del barrio.

"La vivienda popular" es el tipo de construcción que puede encontrarse con mayor incidencia en el barrio Ejidal Sur. Se localiza geográficamente en el límite este de la ciudad; es un barrio relativamente pequeño. Tal y como su nombre indica, existe un Ejidal Norte; ambos quedan divididos por la avenida Juárez, una de las principales vías de Zamora. La génesis del barrio está ligada a la parcelación y venta de terrenos de anterior posesión ejidal. El modelo por el que se realizó el proceso de venta fue el fraccionamiento

por al menos uno de los propietarios, puede ser ayudado por familiares, amigos o profesionales y realizada en diferentes fases según la disponibilidad y necesidad del propietario. 
de parcelas grandes entre los ejidatarios y éstas a su vez en pequeńos terrenos para la venta a particulares.

El comienzo de la construcción del barrio se amparó en una figura jurídica contemplada dentro de la legislación agraria que permitía la creación de "zonas urbanas" para satisfacer las necesidades de los propios campesinos, para su propio asentamiento o el de personas "útiles a la comunidad" que no fueran miembros del núcleo ejidal (Briseño Hurtado 2005, 25). Ante la notable ambigüedad de dicha definición, la venta irregular de este tipo de terrenos fue una de las salidas elegidas por ejidatarios arruinados o que ya habían dejado de dedicarse a la agricultura (Calleja Pinedo 1987, 73); a los compradores se les entregó un contrato de compra venta pero no los títulos de propiedad de la tierra.

A partir de 1992, la nueva ley agraria establece la posibilidad de la circulación mercantil y urbanización de las tierras ejidales mediante los artículos 87 y 89; esto permitió a algunos pobladores comenzar a tramitar sus títulos de propiedad; para el caso del barrio Ejidal Sur estos títulos comienzan a entregarse ya comenzado el siglo xxi. En dicha ley, se establece que estos desarrollos urbanos deberán de hacerse siguiendo la legislación vigente en materia de asentamientos humanos; sin embargo, en la práctica, estas regulaciones no fueron cumplidas frecuentemente. Gran parte de las viviendas construidas en el barrio no contaron con las infraestructuras básicas (agua entubada, electricidad o drenaje) en el momento de su construcción; la dotación de las mismas se hizo con posterioridad y en fases. Además, los propietarios, necesitaron algún proceso para regularizar la posesión de los terrenos en los que se asienta su vivienda.

Así que nos fuimos a vivir así en "obra negra" $[\ldots]$ no se veían los alacranes cuando se ponían. Al tiempo, juntamos un dinero y enjarramos y ya por lo menos se distinguían cuando se paraban.

Doña Rosa (44). Vendedora de comida preparada en la puerta de su casa.

${ }^{2}$ Denomina así a la obra sin recubrir. Nada más los ladrillos y el cemento que los une en las paredes de la vivienda. 


\section{Trabajo POR CUENTA PROPIA EN EL BARRIO}

El trabajo por cuenta propia en el sector informal dentro del barrio Ejidal Sur abarca una cantidad significativa de actividades. El comercio sería la actividad más frecuente dentro del trabajo informal en el barrio. Una buena parte de comerciantes informales se dedican al comercio de productos alimenticios, principalmente preparados. ${ }^{3}$ A esta actividad se dedican tanto hombres como mujeres (es frecuente que lo hagan en pareja si son matrimonio y/o cohabitan). Las mujeres lo hacen en sus casas o en un sitio fijo cerca de la misma. En el caso de los hombres, hay mayor variedad; algunos venden en un puesto fijo que normalmente es su casa o la parte de la calle colindante a la misma y, en otras ocasiones, lo hacen de manera ambulante generalmente en partes más céntricas de la ciudad.

Todos queremos ser comerciantes ¿por qué? para vivir mejor. Porque si estamos con un sueldito nunca... ni para comer nos va alcanzar. Imagínate si él [refiriéndose al caso de un vecino] sigue trabajando con un sueldito mínimo [...] ¿para que le alcanza? Como aquí no hay mucha fuente de trabajo aquí uno se hace pequeño comerciante.

Doña Rosa

El comercio de ropa también es una actividad bastante destacada. Particularmente en el caso de las mujeres. La venta de este bien suele darse en dos variantes muy interesantes. Por un lado la compra de artículos en mercados importantes en el nivel nacional o internacional $^{4}$ que posteriormente son revendidos en locales o domicilios particulares y, por otra, la venta por catalogo a domicilio.

El resto de profesiones más significativas dentro del sector informal podrían resumirse en la prestación de servicios mecánicos y de albañilería para pequeńas reformas en el caso de los hombres y la costura para el de las mujeres. Además se dan otras profesiones como

${ }^{3}$ Los grados de elaboración varían desde papas hervidas con salsa, fruta cortada hasta guisos, carnes y pescados preparados.

${ }^{4}$ Principalmente la ciudad de México y Moroleón (Guanajuato) en el caso del comercio nacional y los Estados Unidos de América en el internacional. 
la crianza de gallos de pelea, herrería, soldadura, fresa y torno, venta de material religioso, alquiler de material de construcción, etcétera.

\section{TRABAJAR EN EL SECTOR INFORMAL}

El término "trabajo informal" fue usado por primera vez en un documento de carácter público por Keith Hart en $1971^{5}$ (Gutiérrez de Hoyos 1997, 17; Roubaud 1995, 54; Flores Robles 1995, 11; Tokman 1991, 15); se incluyó en la obra Employment, incomes and equality in Kenia cuya publicación fue resultado de varios estudios que llevó a cabo la Organización Internacional del Trabajo (orT) en diversos países en vías de desarrollo para examinar el estado de las ocupaciones en los mismos (Flores Robles 1995, 11-12).

Una definición interesante y sintética del mismo es la proporcionada Portes y Castells como aquel tipo de trabajo que "no es regulado por instituciones de la sociedad dentro de un ambiente social y legal en el cual actividades similares si están reguladas" $(1989,12)$. Desde esta perspectiva se rompería la asociación directa entre trabajo informal y otras ocupaciones consideradas ilegales (Márquez Padilla 1989, 10; Roubaud 1995, 24), ya que, aun cuando el trabajo informal quebranta algunas disposiciones legales vigentes en dichos contextos, las actividades que realiza no podrían considerarse intrínsecamente ilegales; pueden considerarse fuera de la ley las maneras en que éstas se realizan (evadiendo impuestos, no registrando sus trabajadores, no superando ciertos controles de calidad, etcétera) pero no las actividades laborales "en sî". ${ }^{6}$ En el barrio está permitido vender comida o ropa, así como reparar piezas automotrices; no obstante, la manera en la que elijen desempeñar esa actividad, está fuera de las pautas normativas estipuladas para hacerlo.

Este tipo de trabajo no puede considerarse como algo completamente aislado de los organismos estatales o normativos ya que, frecuentemente, diferentes instituciones de carácter gubernamen-

${ }^{5}$ François Roubaud afirma que la fecha de publicación de dicho artículo es 1972.

${ }^{6}$ De esta manera se desvincularían actividades como la venta de comida ambulante o la reparación de maquinaría doméstica de otras actividades como el narcotráfico o la extorsión. 
tal toleran, apoyan o fomentan la existencia de trabajo de carácter informal (Roubaud 1995, 24; Portes y Castells 1989, 27; Flores Robles 1995, 16). Es frecuente ver a trabajadores del gobierno municipal o estatal así como a miembros de las fuerzas de seguridad del Estado como clientes de los negocios de los trabajadores informales del barrio. Debido a su mayor visibilidad, es fácil ver a policías del turno de noche cenando en los establecimientos informales de venta de comida que están delante algunas de las viviendas del barrio que, por otra parte, queda muy cerca de la estación de policía federal.

Aquí vienen a cenar clientes de todo tipo. Vienen desde Jiquilpan, Sahuayo... nada más para cenar. Y de todo Zamora... no nomás de acá. De las Fuentes, Arboledas... gente de la presidencia municipal, policía...

Don Braulio (69). Vendedor informal de comida preparada

Además, el trabajo informal no está completamente desvinculado del trabajo formal; incluyendo aquel que se da dentro de los mercados capitalistas (Roubaud 1995, 26). Es más apropiado concebir estas dos formas de trabajo como estrechamente vinculadas y necesariamente interconectadas (Gutiérrez de Hoyos 1997, 19). Los responsables de gran número de empresas del sector formal apoyan y generan diferentes formas de trabajo informal (Cortés 2000, 600-601; Gutiérrez de Hoyos 1997, 23). A través de la externalización de determinadas actividades a trabajadores o empresas informales los dueños de empresas capitalistas consiguen maximizar beneficios y generar una estructura de producción más flexible ante las posibles fluctuaciones en la economía y el consumo. ${ }^{7} \mathrm{El}$ crecimiento del sector informal en Latinoamérica, particularmente desde la década de los setenta del siglo xx, está asociado en parte a la implementación de este tipo de estrategias de producción y maximización de beneficios neocapitalistas.

${ }^{7}$ Este tipo de actividades está ya muy inserto en las estrategias capitalistas de producción. Algunos de los ejemplos más significativos son la externalización o el outsourcing y los trabajos repetitivos o fiddly jobs. 
Complementariamente, conviene remarcar que, aunque el trabajo informal no se ajuste completamente al conjunto de normas legales referentes al trabajo, no debe pensarse que está completamente desregulado (Roubaud 1995, 59). El trabajo informal responde a una "normatividad extralegal" (Ibid., p. 71) en la cual interaccionan de manera flexible y dinámica muchos actores sociales que operan tanto en el sector formal como en el informal.

Como ya eres patrón tienes que estar aquí "a huevo"8. O sea todo el tiempo... al pie del cañón. Si eres empleado pues a veces te la rajas no vas y aquí ya ves que tienes que estar. [...] Hay que cumplir, es lo malo que tienes que estar aquí, que no te puedes salir, si te sales algún lado ya te están esperando.

Ahí te mochas ${ }^{9}$ con el que te trae trabajo; al maestro ese que vino el otro día ahí le di 300 más 150 que me debía de una bomba [...] ahí de su camioneta. [...] Pues tú sabes que si lo tratas bien al cabrón te va a seguir mandando jale. ${ }^{10}$

Don Roberto

El trabajo dentro del sector informal no debe considerarse una manera minoritaria ni residual o marginal de ganarse la vida; actualmente, la mayor parte del trabajo en el nivel mundial tiene lugar fuera del marco formal (Tilly y Tilly 1998, 22). En concreto, para el caso de América Latina según la ort, en el año 2003 se calculaba que $47 \%$ de los trabajadores del ámbito urbano tenían ocupaciones dentro del sector informal (Muñiz Terra 2009, 16); este hecho cuestiona profundamente la existencia de una línea evolutiva laboral moderna según la cual el trabajo seguiría una tendencia hacia la formalización, la mecanización y la concentración (De la Garza Toledo 2009, 113).

En los testimonios recogidos entre los trabajadores por cuenta propia del barrio, se enunciaba de manera reiterada la independencia como valor fundamental para establecerse como trabajadores

\footnotetext{
${ }^{8}$ Obligatoriamente.

${ }^{9}$ Se refiere a pagar.

${ }^{10}$ Trabajo.
} 
por cuenta propia. Varios entrevistados remarcan también las ventajas de no tener patrones, de conseguir la totalidad del beneficio (el plusvalor) de su trabajo para sí mismos, poder crear y fijar sus propias rutinas de trabajo y de ser capaz de conseguir los medios para crear su negocio por cuenta propia sin necesitar apoyo por parte de instituciones públicas o privadas.

Cuando trabajas para otro él se queda casi todo lo que tú trabajas. Luego le dicen a uno: que si te queremos como si fueras de la familia, que te estimamos mucho y la chingada... pero a la hora de pagar igual de codos. ${ }^{11}$ Así, trabajando para uno sabes que si le echas ganas, tú te lo llevas, no vas a estar dando de tragar a otro cabrón con tu trabajo.

Don Roberto

Te va mejor... ¡obvio! Porque tú eres tu patrón y la ganancia que tú tengas no la vas a compartir con nadie.

Doña Rosa

Sin embargo, esta independencia es parcial; eliminan apoyos o deudas con un marco más amplio al mismo tiempo que las consolidan con sujetos de su entorno más cercano a través de prestamos, sistemas de pago diferido y otras prácticas similares que serán abordadas más adelante.

\section{EMPEZAR A TRABAJAR POR CUENTA PROPIA EN EL SECTOR INFORMAL ${ }^{\text {I2 }}$}

El acceso a esta forma de trabajo suele estar ligada a momentos de crisis: ${ }^{13}$ nacimiento de un hijo, cambio de vivienda, problemas con patrones en anteriores trabajos; del mismo modo, en los casos en los que ha habido algunas pausas en la vida laboral, suelen haber estado

${ }^{11}$ Tacańos, agarrados.

${ }^{12}$ Cabe destacar que la mayoría de los trabajadores por cuenta propia entrevistados para este estudio habían tenido trabajo dentro del mercado laboral formal antes de establecerse en el informal. La gran mayoría como empleados por cuenta ajena.

${ }^{13}$ Entendiendo crisis como coyuntura de cambios. No necesariamente en sentido peyorativo. 
vinculadas al mismo tipo de eventos, particularmente en el caso de las mujeres. El caso de éstas parece tener algunas particularidades con respecto al de los hombres; algunas mujeres comienzan trabajando por cuenta propia como un complemento al salario del hombre o simplemente para ocupar su tiempo. Con el paso del tiempo, la condición de mujer trabajadora con un ingreso propio cambia su posición en las relaciones dentro del hogar. Las mujeres entrevistadas percibieron un aumento en su participación en la toma de decisiones y como su opinión comenzó a ser tomada más en cuenta. El trabajo por cuenta propia dentro del sector informal parece ser un punto de acceso al trabajo para mujeres casadas cuyos maridos no tienen demasiada buena opinión acerca de que su mujer trabaje de manera remunerada fuera del hogar.

Le dije a mi viejo que ya no me alcanzaba. Y él me dijo que parecía maquina tragamonedas. Que cuanto más me daba más le pedía. Pero a mí no me alcanzaba $[\ldots]$ con tres muchachos y la renta, los colegios, los uniformes... Y que mi marido me dice que si no me alcanza pues que le busque. Y yo no me lo tomé mal, porque yo sé trabajar. Así que miré lo que tenía en el "refri"... que unos chiles, unos jitomates, cebolla... Y con los diez pesos que me quedaban fui al mercado y esa noche saqué mi mesita y empecé a vender tostadas.

Doña Rosa

Las metas que persiguen los sujetos del barrio que se establecen por cuenta propia son diversas pero con algunas coincidencias; en las entrevistas que yo realicé aparecen de manera recurrente dos. La primera es conseguir una casa propia, en posesión; las maneras en que se puede llegar a materializar esta meta son muy diversas pero destaca la autoconstrucción en fases.

Cuando me regresé de Estados Unidos para Zamora para que Vicente [su hijo] hiciera la comunión, hablé con mi marido: se ocupa que uno estemos allí y otro acá para que hagamos algo. Si nos quedamos los dos allá nunca nos vamos a hacer de una casa.

Dońa Juana (56). Vendedora de ropa comprada en Moroleón, Guanajuato. 
La segunda meta que aparece de manera reiterada es darle una educación a los hijos; se refieren a poder costear económicamente el periodo en el que los hijos quieran dedicarse a estudiar y los gastos asociados a dichos estudios. Es notable que, de los sujetos entrevistados, hay dos cuyos hijos tienen estudios universitarios, bastante escasos en el barrio. Ambos son hijos de mujeres trabajadoras por cuenta propia en el sector informal.

Teníamos la idea de sacar a Vicente adelante, dijo uno... y pues ya hemos cumplido. El muchacho tiene sus estudios... fue a la universidad.

Doña Juana

En cualquier caso, sería inexacto presentar la modalidad de trabajo en el sector informal como algo exclusivamente ventajoso para quienes lo practican. De los trabajadores entrevistados el inconveniente que fue percibido en mayor medida fue la dificultad de gestionar la incertidumbre vinculada a los ingresos y al volumen del negocio.

Aquí, como eres el mismo patrón... el mismo dueño... cabrón cuando no cae trabajo pues andas que te carga la chingada, [...] tienes que pagar las drogas,$^{14} \mathrm{el} \mathrm{material...} \mathrm{[...]} \mathrm{A} \mathrm{veces} \mathrm{que} \mathrm{ni} \mathrm{duermes,} \mathrm{así} \mathrm{pidiéndole} \mathrm{a} \mathrm{Dios}$ que caiga jale. Ayer andaba agüitado ${ }^{15}$ no creas... cabrón así sin feria.

Chacho (42). Mecánico de chasis.

Todos los trabajadores entrevistados valoraban haberse establecido por cuenta propia como algo positivo; solo uno de ellos se planteaba el volver a establecerse dentro de la formalidad pero continuando con la línea del autoempleo. En líneas generales, reconocían que trabajar informalmente les suponía varios "costos vinculados"16 entre los que remarcaban la falta de seguro médico y la imposibilidad de publicitar su negocio. Sin embargo, en el balance

${ }^{14}$ Hace referencia a deudas; particularmente a algo que han comprado a plazos.

${ }^{15}$ Triste.

${ }^{16}$ Siguiendo la terminología que aparece en de Soto, H., El otro sendero. La revolución informal, México, Diana, 1987. 
general que hacían varios de ellos, los costos vinculados a establecerse como trabajadores por cuenta propia dentro del sistema formal serían mayores a los potenciales beneficios.

\section{PráCtICAS DE SOLIDARIDAD}

El segundo elemento que considero particularmente relevante en el estudio de formas de ciudadanía alternativas son las prácticas de solidaridad que se dan de manera informal entre convecinos. Me refiero a un tipo de evento que se da dentro de la cotidianidad, que sucede, no todos los días, sino "un día cualquiera". Sin que necesariamente destaquen en el transcurso de los acontecimientos diarios y repitiéndose con determinada frecuencia, aunque ésta sea ciertamente flexible. Prácticas que se dan entre sujetos que tienen cierto grado de convivencia; que buscan dar respuesta a exigencias del "día a día" de la vida de los individuos que trabajan y residen en el barrio: familiares, amigos, compañeros de profesión y vecinos. En el transcurso de mi investigación ha sido especialmente relevante la incidencia de la última categoría. ${ }^{17}$

Participar en este tipo de prácticas implica entrar en redes de relaciones de reciprocidad que conllevan ciertos derechos y obligaciones. Es en este sentido en el que debe entenderse la propuesta del término solidaridad: un colectivo que utiliza sistemas de apoyo mutuo cuya efectividad depende de la participación comprometida de un determinado volumen de personas. A través de los mismos, especialmente de las que involucran a un mayor número de personas, se establece la idea de la conveniencia de cooperar grupalmente para "salir adelante". La importancia de estas prácticas, más allá de la base económica o material que pudiesen tener, radica en las maneras en que "inciden en la construcción de relaciones sociales, en el forjamiento y reproducción de normas, procedimientos y orden social, en la negociación de identidades" (Villareal 2000, 19). Los sujetos se vinculan entre sí para prestarse apoyo como respuesta a una necesidad subjetiva y, sobre todo, como un deber de carácter moral,

${ }^{17}$ Nótese que la pertenencia a la categoría vecino no es excluyente de las otras. 
cuyo grado depende del grado de cercanía que se establece entre dos sujetos o grupos. Se presupone que todos pueden tener necesidad de apoyo en un momento determinado por lo que todos son susceptibles de prestar apoyo a alguien que lo requiera.

Por tanto, estas prácticas de solidaridad no deben considerarse como hechos intersociales esporádicos relativamente aislados sino como parte de procesos continuos que "se desenvuelven dentro de la sociedad misma” (Sahlins 1977, 205). El acceso a las mismas puede darse en relaciones personales o en redes más amplias y dependerá de la valoración social de la persona que solicite dicho acceso (Villareal 2000 , 29). En caso de contraer algún tipo de deuda a causa de algunas de las prestaciones recibidas, además del componente material que pudiese llevar asociada, será considerada como una deuda de carácter moral (Ibid., p. 25); la valoración social de una persona se pone en juego en el desarrollo de estas prácticas de solidaridad.

Acá en lo de las tandas nadie firma nada, es una acuerdo de confianza nada más. Si alguien falla nos falla a todos [...] pero yo no puedo dejar la tanda sin pagar. Tengo que responder [...] por eso mejor con personas de confianza, que sea gente que responda [...] que tengan palabra.

Dońa Lupe (65). Vendedora de comida preparada en la puerta de su casa.

Es conveniente matizar que las prácticas de reciprocidad no corresponden exclusivamente a grupos sociales al margen del modelo capitalista; no pueden considerarse prácticas en una determinada fase evolutiva de un supuesto desarrollo lineal de las sociedades, sino como coexistentes con otras prácticas y sistemas capitalistas, neoliberales y consumistas (Polanyi en Molina y Valenzuela 2007, 200).

\section{QUE FORMA ADQUIERE LA SOLIDARIDAD}

Mediante estas prácticas pueden intercambiarse bienes y servicios (Conde Bonfil 2001, 73) de manera amplia en el nivel conceptual y temporal. La naturaleza de dichos bienes y servicios puede ser muy variada; sin embargo, el dinero, puesto que es el bien unidad o medida de valor, es un elemento que aparece reiteradamente en las mismas. 
El proceso que involucran este tipo de prácticas podría resumirse en tres fases (Mauss 1979, 204): prestar o dar un servicio o un bien, devolver el mismo cuando sea preciso y aceptarlo cuando éste le sea ofrecido en el momento apropiado por la persona adecuada.

Las prácticas de solidaridad que estudié principalmente en el barrio Ejidal Sur fueron: las tandas, dar y pedir fiado, prestamos de dinero, de herramienta y de capital intelectual y apoyo para celebraciones. Todas ellas tienen dos elementos comunes transversales: la informalidad y la flexibilidad. Esta última es uno de los principales puntos positivos que estos sujetos ven al sistema financiero informal, particularmente en el caso de aquellos sujetos con una alta variablidad de ingresos, como los trabajadores por cuenta propia. La flexibilidad de estas prácticas se adapta satisfactoriamente, tanto a sus realidades cotidianas del "día a día", como a los posibles imprevistos o necesidades puntuales que puedan surgir.

Entre dichas prácticas, las tandas, dar y pedir fiado y los préstamos son las que tienen mayor frecuencia; el apoyo para celebraciones es más ocasional precisamente por su carácter festivo. En dar y pedir fiado y en los préstamos generalmente se establece una relación entre dos partes en las que quien presta y pide se identifican claramente. En el apoyo para celebraciones hay un sujeto o grupo receptor y numerosos sujetos y/o grupos que dan o prestan; en las tandas todos dan cada una de las veces que ésta se lleva a cabo y la posición de receptor se va alternando sucesivamente entre los participantes.

En el caso del apoyo para celebraciones, permite hacer un evento de magnitudes mucho mayores del que podría hacerse sin él; en ocasiones el apoyo de convecinos (que como explicaba anteriormente no es una categoría excluyente de amigos, familiares, compañeros del trabajo, etcétera) determina completamente la posibilidad de realizar el festejo.

Cuando se casó mi hijo el me regaló la hechura. Nada más me cobró la carne. Cuando yo me casé no me cobró ni la carne. Él ha dicho y les ha dicho a los trabajadores yo con doña Rosa jalo porque ella jala.

Igualmente cuando él me pide ayuda. Me dice hoy la voy a contratar, 
cuanto vale un día de su trabajo, porque va a hacer una fiesta o algo. Y a mi me da pena, yo lo hago así nomás porque él me ha ayudado mucho.

Doña Rosa. Sobre la relación que ha establecido con el carnicero que le surte para su negocio.

La práctica de dar y pedir fiado establece un modo de fidelización de la relación cliente-proveedor que, en el caso de trabajadores por cuenta propia, ayuda tanto al vendedor como al comprador a gestionar la incertidumbre asociada a los ingresos procedentes de su labor.

No obstante, son los préstamos y las tandas aquellas prácticas que parecen tener mayor incidencia en la vida cotidiana de los trabajadores por cuenta propia que han sido estudiados. La base del funcionamiento de las tandas es que todos participen puntualmente; en este sistema, que podría calificarse de ahorro diferido, el vínculo que se establece entre los participantes es voluntario y de confianza. Por este motivo la persona que las organiza tiene potestad para decidir, de entre aquellos que quieran participar, quien finalmente lo hace; la persona que desempeńa dicho rol $^{18}$ es quien tiene que responder ante el resto del grupo en caso de que alguno de los participantes incumpla sus pagos. Las tandas permiten un sistema de ahorro que ha sido clave en varios de los casos estudiados para afrontar la inversión inicial que supone establecer un negocio por cuenta propia, para poder responder a la necesidad de renovar utensilios, reparar o reemplazar útiles averiados o adquirir elementos que permitan ampliar o diversificar el negocio.

Siempre lo de las tandas cabrón [...] poco a poco fui comprando el material que ocupaba para establecerme. Me tocaba una tanda chica y que compraba unas bombas, unos sellos, baleros... Y así aguanté dos años. Cuando me tocaba una grande la prensa o herramienta más cara $[\ldots]$ Hasta que a los dos años me salí de la "refa" ${ }^{19}$ y me puse por mi cuenta.

Don Roberto

${ }^{18}$ Prácticamente en la totalidad de los casos que he observado de tandas la persona organizadora era una mujer. En la única excepción que pude observar la organización corría a cargo de un matrimonio.

${ }^{19}$ Abreviatura de refaccionaria. Tienda de repuestos automotrices. 
En el caso de los prestamos sería pertinente establecer una diferenciación entre los préstamos de dinero, por una parte, y los de herramienta y capital intelectual. Mientras que los prestamos de dinero se dan, en líneas generales, de manera bastante similar para la totalidad de los vecinos del barrio, los prestamos de herramienta y capital intelectual tienen una relevancia muy especial para los trabajadores por cuenta propia. Mediante el préstamo de herramienta un trabajador que dirige su propio negocio puede hacer frente a un abanico mucho más amplio de solicitudes por parte de sus clientes, aceptar mayor número de encargos o trabajos de mayor volumen que si tuviese que contar exclusivamente con su propia herramienta. Si a un trabajador le es requerido un servicio para el que no cuenta con el equipamiento adecuado podrá aceptar el trabajo suponiendo que alguno de sus vecinos que sí lo posee va a prestárselo. Si no es un trabajo que le sea requerido con mucha frecuencia, podría ser que no le resulte rentable o asumible costear dicho equipo o herramienta pero, cuando ocasionalmente le sea demandado, puede aceptarlo y cumplir gracias a tener el apoyo logístico de algún vecino.

Algo similar ocurre con el préstamo de capital intelectual. Si algún trabajador se le requiere preparar una comida, realizar una reparación o una construcción que no sabe exactamente cómo hacer, puede tener la certeza de que consultando a alguno de sus vecinos obtendrá una explicación detallada de cómo proceder a realizar el encargo. ${ }^{20}$ Es bastante frecuente que el préstamo de herramienta y de capital intelectual se den simultáneamente.

A veces viene el gordo [vecino mecánico de la misma calle] y me dice [...] oye Roberto para dónde sale este fan clutch. Porque son una chinga, avientan el aire para el motor y si le das para el lado contrario lo puedes quebrar. Y yo se lo explico al cabrón [...] a veces lo trae y hasta yo lo hago.

Don Roberto

${ }^{20}$ Este préstamo correspondería a lo que en el entorno empresarial suele denominarse el know how. Se denomina préstamo porque se espera que puede ser devuelto aunque, por ser algo de carácter intelectual, en general cuando se transmite se regala. 
Esto permite a los pequeños empresarios del barrio Ejidal Sur tener empresas que responden a un elevado número de peticiones por parte de los clientes sin necesidad de realizar más inversión asociada, a excepción de corresponder el apoyo prestado en caso de que éste sea solicitado.

\section{UBICACIÓN TEMPORAL DE LAS PRÁCTICAS DE SOLIDARIDAD}

Las circunstancias en las que se dan este tipo de prácticas de solidaridad varían y son relativamente difíciles de percibir. Algunas son de participación voluntaria, en otras se siente la necesidad de participar por obligación o "compromiso". Además, en determinadas ocasiones, deben ponerse en marcha sin haber sido explícitamente solicitadas como, por ejemplo, en situaciones de emergencia: fallecimientos, enfermedades, etc. (Malengrau 2009, 126). Así, aunque generalmente la participación en las prácticas de solidaridad es voluntaria, no puede afirmarse que lo sea en la totalidad de los casos (Villareal 2000, 32); del mismo modo, el plazo de restitución de las prestaciones o de los bienes suministrados no siempre es determinado con anterioridad.

En caso de que alguien que ha recibido un apoyo no pueda responder a la solicitud de devolución deberá argumentarlo presentando alguna justificación; el constructo ideológico particular que soporta y legitima cada práctica estipulará que impedimentos podrán ser considerados válidos para negar la devolución de la ayuda (Malengrau 2009, 133). Nótese que la condición de prestatario y beneficiario no son, en modo alguno, estáticas; en las relaciones de reciprocidad asociadas a las prácticas cotidianas de solidaridad dichas posiciones se intercambian de manera constante.

\section{Motivación DE LOS PARTICIPANTES}

La génesis de este tipo de prácticas se debe a varios factores. Uno de ellos podría ser la falta de acceso de las familias de escasos ingresos al sistema financiero formal o a algunos de sus productos (Conde Bonfil 2001, 69); en ocasiones si pueden acceder al mismo pero éste 
se produce en condiciones muy desfavorables para ellos como clientes. La informalidad y los grados de incertidumbre que se manejan en ese tipo de periferias urbanas, constituyen otro argumento que sustenta la existencia de este tipo de prácticas. Éstas ofrecen respuestas más rápidas, más flexibles y, en general, menos costosas a los problemas o situaciones que se presentan en la vida cotidiana de los vecinos del barrio. De esta manera, se ajustan en mayor medida a las necesidades de los sujetos de un barrio popular, particularmente aquellos que no pueden predecir con exactitud sus ingresos.

Así es como yo le hago [...] por ejemplo en el mercado lo pago todo de contado $[\ldots]$ yo creo que si me fiarían... pero no me gusta [...] pero en la carnicería sí. Compro el mandado, compro los tacos, compro lo que ocupo y si ya no me quedó para la carne, no lo pago. Ahí lo voy dejando. Él me ha dicho que no me agüite que yo le pague cuando pueda y tenga, que él lo prefiere. Así me la voy mareando.

Doña Rosa

Otro factor que aparece de manera reiterada en la justificación de la existencia de este tipo de prácticas es la presión colectiva. En muchas de estas prácticas no son los individuos, sino las colectividades las que obligan mutuamente (Mauss 1979, 159); algunos participantes presuponen que, en caso de que los compromisos fuesen con ellos mismos o con su propia unidad doméstica, sería más fácil incurrir en el incumplimiento de los mismos por diversas justificaciones.

Si verdad [...] porque las tandas, si en vez de dárselo a dońa Licho voy guardando yo 200 pesos a la semana en una alcancía [...] pues al cabo de diez semanas tendría los 2,000 de la tanda ¿verdad? Pero si uno lo tiene [...] que vamos a comer por ahí hoy [...] y agarras 100 pesos, que si vamos a ver el juego y compras un pomo, ${ }^{21}$ agarras otros 100 y así [...] y al final pues uno no junta nada. Eso es lo bueno de las tandas que te obliga $[. .$. porque como son "a huevo" pues no fallas porque cuando a ti te toca tu

${ }^{21}$ Botella, en este caso se refiere a botella de bebida alcohólica de alta graduación. 
quieres que todos cumplan [...] así que uno también tiene que cumplir para pagar.

Julio (27). Criador de gallos de pelea.

La necesidad, que frecuentemente aparece en el discurso de diferentes entrevistados, podría considerarse como otro factor, pero no el único. Ésta podría fomentar también su participación en otras prácticas o productos dentro del sistema formal como el empeño o hacerles aceptar productos financieros en condiciones muy desfavorables para ellos como clientes; no sería acertado relacionar la necesidad, que es siempre percibida de manera subjetiva, con este tipo de prácticas de solidaridad de una manera causal.

Para los habitantes de barrios como Ejidal Sur existen dos sistemas financieros simultáneos: el formal y el informal. Como expone Mansell para las finanzas populares, el sistema formal está en muchas ocasiones fuera de su alcance y gran parte de su actividad financiera se desenvuelve en un ámbito extralegal $(1995,39)$. Las cantidades de dinero que involucran estas prácticas de solidaridad, no deben considerarse pequeñas en términos totales. Sin embargo, mientras que las prácticas ubicadas dentro del marco formal se dan entre una institución y un sujeto o unidad doméstica en particular, las que se dan el marco informal involucran, en diferentes intensidades y plazos, a redes más extensas de sujetos.

Algunos de los participantes en este tipo de prácticas residentes en el barrio Ejidal Sur afirman conocer que, en términos exclusivamente económicos, no siempre resultan más ventajosas que las que ofrecen los diversos sistemas formales. Esto debe llevarnos a considerar cómo estas prácticas de solidaridad ofrecen otro tipo de cualidades o prestaciones más allá de la rentabilidad económica que las hacen más accesibles y efectivas para muchos de los vecinos del barrio Ejidal Sur.

Y si... nos endrogamos. Pedimos prestado [...] pero no a un banco ni nada. Nosotros con los bancos nunca nos hemos metido. Le pedimos a un compadre y sí... nos prestó. Con rédito pero nos dejó el dinero.

Dońa Amalia (49). Vendedora de comida preparada 


\section{Ciudadanía}

Después de revisar, en líneas generales, las condiciones de vida y trabajo de varios de los individuos residentes en el barrio Ejidal Sur abordaré como considero que el trabajo, las formas de solidaridad y las condiciones específicas de residencia son elementos que tienen especial incidencia en el desarrollo de nuevas formas de relación con las instituciones de carácter estatal y que, en última instancia, definen nuevas maneras de concebirse como ciudadano fuera de las definiciones formales que establecen los estados-naciones.

Lo que podría denominarse como "la invención del concepto moderno de ciudadanía" se ubica en la segunda mitad del siglo XVIII (Pérez Ledesma 2007, 25; Marshall 1998, 78) y estuvo particularmente ligada a los movimientos sociales de finales del siglo, particularmente la Revolución Francesa $1789 .{ }^{22}$ Los dos cambios principales que experimento el concepto "ciudadano" en ese momento fueron, por una parte, complementar los deberes con derechos y, por otra, reinstaurar la capacidad de participación de los ciudadanos en los aparatos legislativos y políticos (Pérez Ledesma 2007, 25-26; Fernández Steinko 2004, 163-165).

Sin embargo, en los dos siglos sucesivos, diversos procesos sociales y económicos han fomentado que cada vez los estados-naciones estén menos equipados para respaldar la vigencia de ese concepto de ciudadanía. Fenómenos como el establecimiento del capitalismo neoliberal como sistema económico predominante en el nivel mundial y la consolidación de la globalización han propiciado la reducción del grado de independencia de los estados-naciones para tomar e implementar decisiones relativas a su propio territorio nacional y sus ciudadanos. Complementariamente, ciertos paradigmas basados en una ciudadanía universalmente inclusiva han sido usados para legitimar discursos igualitarios tratando de hacer menos apre-

${ }^{22}$ La génesis del término ciudadanía puede situarse en las polis de la Grecia clásica donde se vinculaba estrechamente vivir en una ciudad con el estatus de ciudadano (Ricci 2004, 20-28; Pérez Ledesma 2007, 22; Assies 2002, 146). 
ciables las grandes desigualdades en la distribución de derechos y recursos (Holston 2008, 275).

Una definición de carácter general podría servir como punto de partida para entender el uso moderno de la misma. Así, la ciudadanía puede ser considerada como "la relación de pertenencia a una comunidad política, que determina la identidad política de sus miembros, les atribuye deberes y derechos y establece las formas de la obediencia y la participación y dicta las reglas de la inclusión y las exclusión" (Pietro 2000, vii, citado en Pérez Ledesma 2007, 21). Lejos de considerar que esta definición refleja la profunda complejidad del concepto, si puede afirmarse que da cabida a los tres elementos que podemos considerar que la constituyen: adscripción, capacidad de participación y vinculación a derechos y deberes.

\section{Desiguales DESDE El ORIGEN}

La génesis y el desarrollo del concepto ciudadanía han sido asociados con un tipo de sociedad más individualista (Marshall 1998, 83). Sin embargo, la perspectiva basada en el individuo sobre la que se construye la concepción moderna de ciudadanía no implica en todos los casos igualdad entre dichos individuos (Dumont 1982, 15); tampoco conlleva necesariamente el hecho de que la categoría ciudadano incluya a todos los sujetos que habitan en un territorio determinado. Es una categoría "universalmente inclusiva y generalmente desigual" (Holston 2008, 40) que nace asociada a los estados-naciones; simultáneamente incluyente y excluyente (Ibid.). Tiene ambas funciones: dotar a grupos de sujetos de la condición de iguales y a otros grupos de la condición de no iguales; la desigualdad es intrínseca al concepto.

Las primeras acepciones del término ciudadano se especializaron en excluir a sujetos nacidos dentro de la misma división territorial. Los iletrados, los esclavos, las mujeres, los no terratenientes y los delincuentes fueron algunos de los grupos que con mayor frecuencia fueron excluidos de la categoría. El derecho que con mayor frecuencia se les negaba a estos colectivos era la capacidad de voto (Salman 2002); Los criterios que con mayor frecuencia se 
consideraron restrictivos para la membresía fueron la religión, la raza y el género (Holston 2008, 60, 89). Además, en ocasiones se incluían criterios morales para justificar la inclusión o exclusión de los ciudadanos.

Concretamente, para el caso mexicano, a partir de la crisis fiscal del Estado en 1982, se empiezan a gestar cambios profundos que repercuten en la ciudadanía (Lomnitz 2000, 142) Sumido en movimientos sociales y económicos amplios, el Estado cada vez tiene un papel menos relevante en la formación cultural del ciudadano (Zárate Hernández 2002, 412). Se produce un doble movimiento con respecto a la categoría de ciudadano en México. A la vez que el concepto se va ampliando, a través de diferentes textos jurídicos incluyendo cada vez a más parte de la población hasta llegar a prácticamente la totalidad de los residentes en el país, el estatus que conlleva la pertenencia al grupo de los ciudadanos mexicanos ha ido perdiendo significado. Los derechos y deberes asociados a la ciudadanía aparecen cada vez más detallados en el nivel legal y, al mismo tiempo, la categoría en sí misma parece correr el riesgo de ser vaciada conceptualmente (Lomnitz 2000, 146) o de convertirse en lo que ha sido denominado como "ciudadanía flaca" (Salman 2002, 127).

En conexión con este proceso de inclusión generalizada y vaciado conceptual comienzan a desarrollarse ciudadanías alternativas. $\mathrm{Al}$ no sentirse identificados con las definiciones formales de ciudadanía, un número considerable de sujetos, buscan otras formas de adscripción y expresión que operen de manera más adecuada a sus condiciones específicas de vida.

\section{Ciudadanías alternativas}

En términos muy generales, las formas alternativas pueden considerarse como un tipo de respuesta a las múltiples contradicciones existentes entre el orden normativo formal o legal y la realidad (Lomnitz 2000 , 16). La principal contradicción que se afronta es la coexistencia de criterios y discursos oficiales que remarcan la igualdad entre ciudadanos con prácticas que fomentan la existencia de una sociedad 
altamente jerarquizada (DaMatta 1997, 71). El conflicto generado estimula el cuestionamiento de dicha oficialidad, especialmente por parte de aquellos colectivos menos centrales a nivel normativo (Salman 2002, 132).

Si revisamos los tipos de ciudadanía alternativa que han sido estudiados por otros autores considero que cinco propuestas podrían ser particularmente ilustrativas para el estudio de las formas de adscripción ciudadana en un barrio de la periferia de una ciudad media latinoamericana.

La primera que voy a presentar es la "ciudadanía cultural" planteada por Rosaldo, especialista en el estudio de minorías culturales en Estados Unidos. Según esta propuesta, las nuevas formas de ciudadanía cultural reafirman el derecho a ser diferente con respecto a las normas de la comunidad dominante sin poner en riesgo el derecho a pertenecer a la misma con plena capacidad para participar en los procesos democráticos que se den en el marco del Estado-nación (1997, 242).

Tres elementos de esta propuesta tendrían una estrecha conexión con el colectivo estudiado en Ejidal Sur. Primero, no todos los ciudadanos se ven necesariamente reflejados en lo que quienes representan a las instituciones centrales consideran el bien común.

Si tú te das cuenta... ¿ ¿dónde ha hecho inversión el gobierno municipal? ¿Qué es lo que están arreglando ahora? Las colonias de gente con feria. Han arreglado allá por Los Laureles, han puesto el pavimento nuevo... ¿por qué? Si ya estaba bien. Pero es lo que te digo... sólo gastan donde vive la gente con dinero.

Don Braulio

Segundo, a pesar de la heterogeneidad inherente a esta definición de ciudadanía, reconoce la acción colectiva como herramienta principal para el progreso de la comunidad y de sus individuos, reafirmando la posibilidad de existencia de formas de ciudadanía que incidan a la vez en el plano colectivo e individual (Ibid., p. 258). Tercero, la nueva forma de adscripción o ciudadanía no entra en conflicto con el sentimiento de pertenencia nacional. 
Otra propuesta teórica sobre ciudadanía alternativa es la realizada por Holston denominada "ciudadanías urbanas insurgentes". Este concepto se refiere a la transformación política que ocurre cuando la convicción de tener ciertos derechos relativos a la ciudad convierte a los residentes en "ciudadanos activos que movilizan sus demandas a través de organizaciones con base local que confrontan los regímenes afianzados de desigualdad ciudadana" $(2008,4)$. Este planteamiento remarca la particular vinculación que tiene la ciudadanía con los procesos de construcción de viviendas y barrios en las periferias urbanas que él denomina la "ciudad autoconstruida". ${ }^{23}$

Lo poco que hemos conseguido en el barrio lo hemos conseguido nosotros. La luz, el drenaje, el teléfono, el pavimento... estuvimos en friega.

Don Braulio

Holston considera las periferias urbanas particularmente relevantes en el estudio de las ciudadanías por cuatro aspectos. Primero, por el papel protagonista del contexto urbano en la génesis, construcción y desarrollo del concepto ciudadanía. En segundo lugar, el crecimiento rápido de las áreas urbanas genera una acentuación de las desigualdades entre los habitantes de las mismas (Holston 2008, 107). Tercero, los barrios populares, muy numerosos en las periferias urbanas latinoamericanas, suelen haber pasado (o estar pasando) por conflictos relacionados con la propiedad del suelo y/o de los inmuebles y con la conversión del terreno en el que están asentados en suelo de tipo urbano o edificable (Ibid., p. 208). Asimismo, en muchas ocasiones han tenido o tienen un proceso largo y complejo para reivindicar y conseguir la dotación de dichos asentamientos con los servicios e infraestructuras básicas para hacerlos habitables y

${ }^{23}$ Holston utiliza este concepto para referirse a aquellos asentamientos en los que la gran mayoría o la totalidad de las inmuebles e infraestructuras han sido construidos por los propios pobladores. Yo prefiero utilizar el concepto "autoconstrucción en etapas" por dos motivos. En primer lugar no toda la ciudad se construye de esta manera; en segundo lugar, la construcción de viviendas de ciertos barrios, además de ser realizada por los propios habitantes, suele darse en fases, más o menos distanciadas, según las condiciones y posibilidades del grupo o el individuo que las habita. 
garantizar así parte de las condiciones de vida que propone la "dimensión social” ${ }^{24}$ de la categoría de ciudadanía.

Las similitudes de las periferias que estudió Holston en Sao Paulo son extraordinarias con respecto a Ejidal Sur. El alto nivel de semejanza existente entre dos casos relativamente alejados en el nivel geográfico puede llevarnos a pensar que existe un perfil relativamente común para algunas periferias latinoamericanas. Siguiendo la propuesta de Holston, Ejidal Sur, tiene un potencial muy alto para el desarrollo de formas de ciudadanía alternativa por la lucha por los títulos de propiedad de sus tierras, las reivindicaciones para la dotación de servicios y las corrientes migratorias de las que el barrio es fruto.

En este intento de reivindicar el derecho a la ciudad y el acceso a la propiedad privada de la tierra se da lo que Holston denomina la "paradoja de la ocupación de la tierra"; Ésta consiste en que la ocupación ilegal o irregular acaba convirtiéndose en un paso hacia la regularización; es una muestra significativa de que lo ilegal puede ser o es factible (Ibid., pp. 206-207) y puede constituir un paso hacia un objetivo legal o formal. En otros casos, el cumplimiento de la ley conlleva procesos de una complejidad muy elevada, que pueden llegar a estimular el fraude (Ibid., p. 219); en este sentido, cada "complejo procedimiento legal" es una oportunidad para instituir maniobras extralegales e intermediarios (Ibid., pp. 228-229). Para un colectivo como el estudiado en el barrio Ejidal Sur, la informalidad se vuelve en ocasiones la vía predominante en el terreno laboral, de apoyo y solidaridad y residencial.

Otra propuesta con claras conexiones al fenómeno estudiado es la de DaMatta para el caso brasileño. Para él ser ciudadano es algo que se aprende, estando demarcado por expectativas de comportamientos singulares (1997, p. 66). Ubica las relaciones, el prestigio y los sistemas de lealtades múltiples como elementos centrales de la ciudadanía construida que existe en dicho país; liga las formas de filiación a la sociedad brasileña con las formas de relación que típicamente existen en el espacio privado que corresponde a la casa

${ }^{24}$ Según las tres dimensiones civil, político y social que plantea Marshall (1998) para la ciudadanía moderna. 
(Ibid., p. 86). De esta manera, se establece un grado de "ciudadanía cero" o "ciudadanía degradada" sobre el que, con base en que tan reconocidas o prestigiosas sean las relaciones sociales de cada individuo, los brasileños tienen que construir su ciudadanía para poder desenvolverse en una sociedad altamente desigual y jerarquizada; la frase con la que DaMatta resume la situación de la ciudadanía para el caso brasileño sería "sabe com quem está falando?" (Ibid., p. 79).

A partir de estos planteamientos, Claudio Lomnitz trata de hacer una aproximación al caso mexicano. A pesar de la existencia de una opinión generalizada acerca de que los mexicanos dependen en un grado muy alto de sus relaciones sociales, para Lomnitz sería ingenuo pensar que equivale a un grado de ciudadanía cero; esta visión debería ser complementada con "una interpretación de la relación entre las definiciones legales e institucionales de ciudadanía y su elaboración cultural en la interacción social” (2000, 130-131). Así, crítica el planteamiento de DaMatta argumentando que su explicación no clarifica las formas en que el concepto ciudadanía se colma y se vacía de contenidos (Ibid., p. 145), exponiendo como, en el caso de México, la ciudadanía se ha visto profundamente afectada por procesos de fetichización y contracción del Estado que, en diferentes momentos de la historia del país, dieron y restaron importancia al estatus de ciudadano.

Ambas propuestas remarcarían una visión de la ciudadanía relacional; basada en los contactos que posee cada sujeto. Proponen una visión dinámica de la ciudadanía en la cual tendrían un peso específico las diferentes conexiones que tiene cada individuo; pondría de manifiesto que, efectivamente, el sentimiento ciudadano es algo que se construye y que, en dicha construcción, el tipo de eventos que tiene mayor peso están más vinculados a acciones cotidianas como el trabajar o formas de solidaridad que a eventos ocasionales como pueden ser el voto electoral. Los vecinos del barrio estudiado expresan la necesidad de relacionarse para hacer valer sus derechos y, especialmente, cómo la acción en colectividad les protege y reivindica.

Por último, Salman, plantea que, ante la distancia existente entre la ciudadanía oficial y la vida cotidiana de la gente, la ciudadanía se ha convertido en algo que se recibe de manera pasiva pero que no se 
ejerce $(2002,135-136)$. Esto supondría una autoexclusión relativamente voluntaria por parte de los colectivos que sufren con mayor intensidad dicho distanciamiento, tanto del dominio de las regulaciones legales y formales, como de la participación en espacios públicos y políticos regidos por prescripciones formales (Ibid., p. 135). Esta perspectiva comparte la idea de buscar relaciones personales para suplir las carencias o contradicciones que plantea el sistema jurídico, pero sugiere que, en la medida de lo posible, los ciudadanos evitan tratar con el sistema legal (Ibid.). En caso de, necesariamente tener que recurrir al mismo, se hace a través de intermediarios o brookers convirtiendo lo político en una "relación con alguien y no con algo" (Ibid.).

A través de este planteamiento habría que entender como la autoexclusión se refiere a la propuesta normativa. Y se aplicaría, no sólo al texto legal de la misma sino a otras instituciones sobre las cuales se apoya dicha definición de ciudadanía como el mercado de trabajo formal y las instituciones financieras. El rechazar una forma determinada de ciudadanía no significa rechazar el concepto en sí. Los habitantes del barrio Ejidal Sur siguen percibiéndose como parte del Estado mexicano con obligaciones y derechos pero los han redefinido, con base en su realidad cotidiana, al lugar donde residen $\mathrm{y}$ al tipo de relaciones que prima en su cotidianidad.

\section{Conclusiones}

A lo largo del artículo se ha podido seguir un breve desarrollo del concepto ciudadano. Éste fue vinculado en un principio a diversos elementos como el trabajo, el estado civil, la raza, el sexo o el patrimonio. Posteriormente, se fue desmarcando de esos criterios en su camino hacia la categoría "universalmente inclusiva" que conocemos hoy. El cajón de sastre que parecía ser la ciudadanía fue vaciándose paulatinamente de contenido y criterios de admisión mientras se llenaba progresivamente de sujetos; cada vez más individuos tenían el derecho de llamarse ciudadanos a la vez que, cuantos más sujetos entraban en la categoría, ésta iba perdiendo progresivamente el valor pragmático de sus contenidos. 
La ciudadanía es un fenómeno difícil de estudiar. Se han hecho aproximaciones vinculándola con el ejercicio al voto, al reclamo de ciertos derechos o a la manera de organización que tienen algunas situaciones "espontáneas" como, por ejemplo, hacer fila esperando en un determinado negocio. Sin embargo, propongo que, desde la perspectiva de las ciencias sociales, dicha categoría vuelva a ser vinculada a fenómenos como el trabajo o las diversas maneras de apoyo mutuo. Particularmente, en el caso de aquellos sujetos que han optado por elegir vías alternativas con respecto a las propuestas oficiales.

Asimismo, considero que para estudiar los cambios experimentados en las formas de concebir y ejercer la ciudadanía se debe prestar una atención especial a los colectivos alejados de la norma o minoritarios; no significa que necesariamente sean minorías en sentido numérico, pero si grupos secundarios desde el punto de vista normativo. Este tipo de sujetos pueblan con mucha frecuencia las periferias urbanas, como en caso del barrio Ejidal Sur presentado en este artículo. Dichas periferias en Latinoamérica son particularmente interesantes ya que, en el proceso de las reivindicaciones que tuvieron que hacer (o hacen) para conseguir ciertos derechos en sus viviendas y barrios, generaron una cierta conciencia acerca de la necesidad de un relativo grado de agencia para conseguir el ejercicio o disfrute de sus derechos; éstos, no solamente se reciben, sino que tienen que ser reclamados o, incluso, exigidos.

Las ciudadanías alternativas en Latinoamérica podrían ubicarse como las formas de ser ciudadano que un elevado número de sujetos que no se sienten identificados con las definiciones formales de la categoría han adoptado sin que ello cuestione su pertenencia nacional. Estas tendrían por principales características: la desvinculación de instituciones de carácter estatal para revincularse a grupos más pequeńos y cercanos en el espacio con quienes se comparten las condiciones de vida cotidiana y se abordan las problemáticas relativas al "día a día"; una concepción dinámica de la condición de ciudadano donde adquieren una especial dimensión las relaciones sociales y la agencia para la reivindicación de los derechos asociados a la misma; finalmente, la elección de la informalidad como modo flexible y mejor adaptado para abordar las cuestiones relativas a sus 
realidades cotidianas así como vía legítima para lograr las metas vitales que consideran fundamentales: tener un trabajo que les permita ganarse la vida dignamente, poseer una vivienda y costear la educación de sus hijos.

El asunto laboral es particularmente interesante; determinados sujetos, que ya han tenido una o varias ocupaciones dentro del mercado formal del trabajo, deciden establecerse por cuenta propia en el sector informal sin que este movimiento implique la renuncia a su condición de ciudadano. El trabajo que les es ofrecido a través de las instituciones formales no les resulta lo suficientemente atractivo debido a diversos motivos: escasez salarial, dificultad para compaginar el trabajo con las actividades domésticas y de crianza, la existencia de techos de cristal, ${ }^{25}$ etc. A través de la creación de sus propios puestos de trabajo, fuera del mercado formal, los individuos expresan cierta disconformidad con el mercado laboral que les es ofrecido y, simultáneamente, demuestran capacidad de agencia.

Del mismo modo, la participación en prácticas de solidaridad basadas en el apoyo mutuo, expresa capacidad para crear y poner en marcha alternativas a las vías formales para el ahorro, los prestamos monetarios, de utensilios y de herramientas, para la celebración de fiestas y, sobre todo, la gestión de la incertidumbre. A través de este tipo de prácticas, se refleja cómo la propuesta de las ciudadanías alternativas concibe cómo determinados individuos pueden desvincularse de ciertas instituciones de carácter estatal pero, no por ello, pasan a ser sujetos aislados en el espacio social. Éstos se anclan a nuevos grupos mucho más pequeños, con los que comparten gran parte de sus condicionantes sociales y una realidad cotidiana muy similar; este tipo de grupos se pueden ubicar de manera más intensa en las relaciones que se dan en el espacio inmediato del lugar en que se encuentra la residencia de dichos sujetos: en las relaciones vecinales.

Por otra parte, la informalidad es un concepto que atraviesa los dos elementos relacionados con la ciudadanía expuestos en este artículo. La misma también es uno de los ejes constitutivos de las for-

${ }^{25} \mathrm{El}$ concepto se refiere a la existencia tácita de límites de ascensión en las diferentes jerarquías laborarles y salariales en función de condiciones como el género, la capacitación o la pertenencia étnica. 
mas de ser ciudadano alternativo; disgreden de la normatividad porque experimentan como ésta no les representa o como, de manara reiterada, no se dan los mecanismos necesarios para que los elementos afirmados en los discursos políticos oficiales acerca de la igualdad y del "universalismo ciudadano" puedan ser llevadas a la práctica.

No debe ser olvidado que, desde su origen, la ciudadanía es una categoría creada para marcar diferencias entre sujetos. A pesar de los múltiples discursos inclusivos que transmiten una cierta idea de igualdad para la ciudadanía, las diferencias sociales tienden a deslegitimar dichos discursos; en las sociedades donde existe mayor desigualdad o una jerarquización social más intensa, el descrédito de tales afirmaciones será mayor. Por este motivo, planteo que, tales grados de disonancia propician la aparición de diferentes modos de concebir y ejercer la ciudadanía; particularmente en sociedades y contextos donde las desigualdades sociales son más palpables, como, por ejemplo, en ciertas periferias urbanas latinoamericanas.

La ruptura con las instituciones de carácter estatal se produce de manera más intensa en la resolución de las vicisitudes asociadas al "día a día". En cualquier caso, no se plantea que la desvinculación de dichos sujetos con las instituciones estatales sea completa; siguen recurriendo a ellas y a ciertos elementos de carácter asistencial que provienen de las mismas. Los periodos de escolaridad de los hijos, las fases de equipación de viviendas y barrios y las fiestas religiosas y civiles parecen ser los momentos en los que existe una relación más clara con instituciones de carácter estatal. Por tanto, puede ser de gran utilidad en el estudio de las formas de ejercer y concebir la ciudadanía, reenfocar el estudio de la misma hacia colectivos fuera de la normatividad formal y hacer mayor énfasis en el ejercicio de ésta en prácticas de carácter más cotidiano, en lugar de centrarse en prácticas eventuales como el ejercicio del voto. Probablemente, el trabajo y las prácticas de solidaridad no son los dos únicos elementos de la vida cotidiana que pueden incluirse en el estudio de las formas de ciudadanía alternativas en el plano de la cotidianidad. Sin embargo, éstos parecen un buen punto de partida ya que pueden encontrarse en la mayoría de los contextos en los que la ciudadanía es susceptible de considerarse y estudiarse. 


\section{BIBLIOGRAFÍA}

Assies, Willem, "Apuntes sobre la ciudadanía, la sociedad civil y los movimientos sociales", en Willem Assies, Marco Antonio Calderón Mólgora y Ton Salman, Ciudadania, cultura politica y reforma del Estado en América Latina, Zamora, El Colegio de Michoacán, Instituto Federal Electoral Michoacán, 2002, 145-176.

Briseño Hurtado, R., Sepultando los tesoros de Zamora. Urbanización de las tierras agrícolas, Zamora, Tesis inédita de El Colegio de Michoacán, 2005.

Calleja Pinedo, Margarita, Los empresarios y las transformaciones socioeconómicas de un centro urbano regional: Zamora, Mich., Zamora, Tésis inédita de El Colegio de Michoacán, 1987.

Conde Bonfil, Carola, ¿Depósitos o puerquitos? Las decisiones de ahorro en México, México, El Colegio Mexiquense, 2002.

CortÉs, Fernando, "La metamorfósis de los marginales: la polémica sobre el sector informal en América Latina”, en Enrique de la Garza Toledo, Tratado Latinoamericano de Sociología del Trabajo, México, El Colegío de México, FlACSO, UAM, 2002, 592-618.

DaMatta, Roberto, A casa \& a rua, Rio de Janeiro, Rocco, 1997.

De la Garza Toledo, Enrique, "Hacía un concepto ampliado de trabajo", en Julio C. Nefta, Enrique de la Garza Toledo, y Leticia Muñiz Terra, Trabajo, empleo, calificaciones profesionales, relaciones de trabajo e identidades lavorales, Buenos Aires, Clacso, 2009, vol. 1, 111-140.

Dumont, Louis, Homoaequalis: génesis y apogeo de la idelogía económica, Taurus, 1982.

Flores Robles, Manuel, Economía Informaly Política: el Caso de los Mercados Ambulantes en Guadalajara, Guadalajara, Tésis Inédita de la Universidad de Guadalajara, 1995.

Fernández Steinko, Aramando, Clase, trabajo y ciudadanía. Introducción a la existencia social, Madrid, Biblioteca Nueva, 2004.

González y González, Luis, Zamora, México, El Colegio de Michoacán, 2009 [1978].

Gutiérrez de Hoyos, G., El comercio callejero en el Centro Histórico, México, Tésis Inédita-uAm Iztapalapa, 1997. 
Holston, James, Insurgent citizenship. Disjunctions of democracy and modernity in Brazil, Princetown, Princetown University Press, 2008.

Lomnitz, Claudio, La construcción de la ciudadanía en México, Metapolítica, 4, 2000, 128-149.

Malengrau, Jacques, Parientes, paisanos y ciudadanos en los Andes de Chachapoyas, Cuzco, Instituto Francés de Estudios Andinos, 2009.

Márquez Padilla, Carlos, La ocupación informal urbana en México: un enfoque regional, México, Fundación Friedrich Ebert, OEKO-México, 1989.

Mansell Carstens, Catherine, Las finanzas populares en México. El redescubrimiento de un sistema financiero olvidado, México, Milenio, 1995.

Marshall, T., Citizenship and Social Class, Alianza, 1998.

Mauss, Marcel, Sociología y Antropología. Madrid, Tecnos, 1979.

Molina, José Luis y Hugo Valenzuela, Invitación a la antropología económica, Barcelona, Bellaterra, 2007.

MuñIz Terra, Leticia, "Nuevos y viejos escenarios en el mundo laboral latinoamericano. Distintas miradas para su estudio", en Julio C. Nefta, Enrique de la Garza Toledo y Leticia Muñiz Terra, Trabajo, empleo, calificaciones profesionales, relaciones de trabajo e identidades laborales, vol. 1, Buenos Aires, CLACsO, 2009, 15-22.

Ortiz, Víctor Manuel, El barrio bravo del Madrigal, México, El Colegio de Michoacán, 1990.

Pérez Ledesma, Manuel, La invención de la ciudadania moderna, en M. Pérez Ledesma, De súbditos a ciudadanos. Una historia de la ciudadanía en España, Madrid, Centro de Estudios Políticos y Constitucionales, 2007, 21-58.

Portes, Alejandro y Castells, Manuel, "World Underneath: The origins, dynamics, and effects of the informal economy", en Alejandro Portes, Manuel Castells y Lauren A. Benton, The informal economuy in avance and less developed countries, Maryland, Londres, The John's Hopkins University Press, 1989.

Ricci, David M., Good Citizenship in America, Cambridge, Cambridge University Press, 2004. 
Rosaldo, Renato, Ciudadanía cultural y minorias latinas en Estados Unidos, en R. Wincour, Culturas Politicas a fin de siglo, México, Flacso, 1997.

Roubaud, François, La Economía Informal en México. De la esfera doméstica a la dinámica macroeconómica, México, orstom, INEGI, Fondo de Cultura Económica, 1995.

Salman, Ton, "Ciudadanía, entre pluralidad y universalidad; consideraciones conceptuales en torno a la actualidad de un fenómeno", en Willem C. Assies y Ton Salman, Ciudadania, cultura politica y reforma del Estado en América Latina, Zamora, El Colegio de Michoacán, Instituto Federal Electoral Michoacán, 2002, 125-144.

SAHLins, Marshall, Economía de la edad de piedra, Madrid, Akal, 1977.

Tilly, C., y Tilly, C., Work under Capitalism, Colorado, Oxofrd, Westview Press, 1998.

Tokman, Victor E., El sector informal en América Latina, México, Conaculta, 1991.

Villareal, Magdalena, "Deudas, drogas, fiado y prestado en las tiendas de abarrotes rurales", Desacatos (3), 2000, 18-39.

Zárate Hernández, José Eduardo, "Ciudadanía, comunidad y modernidades étnicas" en Willem Assies, Marco Antonio Calderón Mólgora y Ton Salman, Ciudadanía, cultura politica y reforma del Estado en América Latina, Zamora, El Colegio de Michoacán, Instituto Federal Electoral Michoacán, 2002, 407-427.

FECHA DE RECEPCiÓn DEL ARTÍCULO: 22 de febrero de 2011

FECHA DE ACEPTACIÓN Y RECEPCIÓN DE LA VERSIÓN FINAL: 10 de octubre de 2011 